\title{
Interpopulation variation in pollinators and floral scent of the lady's-slipper orchid Cypripedium calceolus $\mathrm{L}$.
}

\author{
Herbert Braunschmid ${ }^{1} \cdot$ Bernadette Mükisch $^{1} \cdot$ Thomas Rupp $^{1} \cdot$ Irmgard Schäffler $^{1}$. \\ Pietro Zito ${ }^{2} \cdot$ Daniele Birtele $^{3} \cdot$ Stefan Dötterl $^{1}$ (D)
}

Received: 28 October 2016 / Accepted: 4 March 2017 / Published online: 9 April 2017

(c) The Author(s) 2017. This article is an open access publication

\begin{abstract}
Floral scent is a key mediator in many plantpollinator interactions. It is known to vary not only among plant species, but also within species among populations. However, there is a big gap in our knowledge of whether such variability is the result of divergent selective pressures exerted by a variable pollinator climate or alternative scenarios (e.g., genetic drift). Cypripedium calceolus is a Eurasian deceptive lady's-slipper orchid pollinated by bees. It is found from near sea level to altitudes of $2500 \mathrm{~m}$. We asked whether pollinator climate and floral scents vary in a concerted manner among different altitudes. Floral scents of four populations in the Limestone Alps were collected by dynamic headspace and analyzed by gas chromatography coupled to mass spectrometry (GC/MS). Flower visitors and pollinators (the subset of visitors with pollen loads) were collected and identified. Preliminary coupled gas chromatographic and electroantennographic measurements with floral scents and pollinators revealed biologically active components. More than 70 compounds were detected in the scent samples, mainly aliphatics, terpenoids, and aromatics. Although several compounds were found in all samples, and all samples were dominated by linalool
\end{abstract}

Handling editors: Isabel Alves dos Santos and Isabel Machado.

Stefan Dötterl

stefan.doetterl@sbg.ac.at

1 Department of Ecology and Evolution, Plant Ecology, University of Salzburg, Hellbrunnerstr. 34, 5020 Salzburg, Austria

2 Department of Biological Chemical and Pharmaceutical Sciences and Technologies, University of Palermo, Palermo, Italy

3 Centro Nazionale per lo Studio e la Conservazione della Biodiversità Forestale "Bosco Fontana”, Marmirolo, Italy and octyl acetate, scents differed among populations. Similarly, there were strong differences in flower visitor spectra among populations with most abundant flower visitors being bees and syrphid flies at low and high altitudes, respectively. Pollinator climate differed also among populations; however, independent of altitude, most pollinators were bees of Lasioglossum, Andrena, and Nomada. Only few syrphids acted as pollinators and this is the first record of flies as pollinators in C. calceolus. The electrophysiological tests showed that bees and syrphid flies sensed many of the compounds released by the flowers, among them linalool and octyl acetate. Overall, we found that both floral scent and visitor/pollinator climate differ among populations. We discuss whether interpopulation variation in scent is a result of pollinator-mediated selection.

Keywords Deceptive pollination .

Electroantennography $\cdot$ Dynamic headspace $\cdot$ Pollinator climate

\section{Introduction}

The majority of angiosperms is pollinated by animals, mostly insects (Ollerton et al. 2011). The pollinator climate (composition, abundance, and efficiency of pollinators; Grant and Grant 1965) of a plant species often varies among populations and potentially contributes to the evolution of pollination ecotypes, i.e., forms adapted to the local pollinator fauna, especially if differences in the pollinator climate among populations are temporally and spatially stable in an evolutionary timescale (Johnson 2006). Such ecotypes often differ in floral characteristics which allow recognizing subspecies or other intra-specific taxa (e.g., Johnson 1997). Such variations in floral 
traits are not only caused by qualitative shifts in the pollinator spectrum, but more often by a gradual, quantitative variation in the availability of pollinator species (Aigner 2001; Waser 2001).

The flowers of animal-pollinated plants typically advertise their presence by visual and olfactory cues (Chittka and Raine 2006). Olfactory cues are most important for plants pollinated at night (Cordeiro et al. 2017; Dobson 2006; Dötterl et al. 2012), and for highly specialized pollination systems (Heiduk et al. 2016; Milet-Pinheiro et al. 2013; Schäffler et al. 2015; Schiestl et al. 1999).

Several thousand scent compounds are known so far (Knudsen et al. 2006). As with other floral traits, floral scents are known to vary within species, both within and among populations (Dötterl et al. 2005; Chartier et al. 2013; Mant et al. 2005; Stökl et al. 2009; Sun et al. 2014), and this variability is strongly suggested to have a genetic basis (e.g., Andargie et al. 2014; Friberg et al. 2013; Zu et al. 2016). However, little is known whether such genetic variability is the result of divergent selection or other scenarios (e.g., drift). The effectiveness of an olfactory signal depends on how well it matches the pollinator's perceptive abilities, and these olfactory traits are thus expected to diverge between plant populations experiencing different pollinator environments. Indeed, plants experiencing different pollinators among population were found to produce population-specific scents and likely be adapted to the locally available pollinator climate (Mant et al. 2005; Stökl et al. 2009; Sun et al. 2014).

Although typically involved in mutualistic interactions with their pollinators, 4-6\% of plants are pollinated by deceit (Renner 2006). The flowers of such plants signal the presence of a reward by visual, olfactory, thermal, and/or tactile cues without providing it. Populations of deceptive plants are believed to be more variable than populations of rewarding species in traits associated with pollinator attraction. This is because deceived pollinators then have more difficulties in learning to avoid the deceptive plant and discriminate it from rewarding resources (Ackerman et al. 2011).

A widespread deceptive plant in Eurasia is Cypripedium calceolus L. (Orchidaceae). It occurs in central and northern parts of Europe and Asia, where it spans an altitudinal gradient from near sea level to $2500 \mathrm{~m}$ a.s.l. (Cribb 1997). It is known from previous studies that the pollinators of the trap flowers of $C$. calceolus are predominantly various solitary bees from the genera Andrena, Lasioglossum, and Halictus (Kull 1999; Nilsson 1979 and references therein) which are attracted by visual and olfactory floral cues (Daumann 1968; Nilsson 1979). However, it is unknown whether the pollinator climate of $C$. calceolus varies among altitude as shown for other plants (e.g., Pellmyr 1986; Sun et al. 2014).
Here, we examined four populations of $C$. calceolus between 600 and $1450 \mathrm{~m}$ a.s.l. and asked whether pollinators and floral scents differ among populations. In preliminary analyses, we also determined biologically active compounds in flower visitors/pollinators. In detail, we (i) collected scent from flowers by dynamic headspace and analyzed samples by thermal desorption (TD) gas chromatography and mass spectrometry (GC/MS), (ii) recorded insects trapped in the flowers and those being potential pollen vectors, and (iii) used gas chromatography coupled to electroantennographic detection (GC/EAD) to determine electrophysiologically active floral scent compounds in several flower visitors/pollinators. As shown in other species, we predict that there are differences in scent and flower visitors/pollinators among populations (see above) of $C$. calceolus, and that antennae of different insects respond to a different set of compounds (compare with Jürgens et al. 2014). We discuss whether results point to local pollinator adaptation in olfactory cues in $C$. calceolus.

\section{Materials and methods}

\section{Plant species}

Cypripedium calceolus L. (C. calceolus, ssp. calceolus in Bergström et al. 1992) is a pollen-limited perennial orchid (Kull 1998; Blinova 2002) distributed across the boreal and temperate zones of Europe and Asia. It is found in a variety of habitats including open to medium-shaded deciduous and coniferous forests, and alpine meadows and rubble, predominantly on calcareous soil (Cribb 1997). It is one of the biggest European orchids with a stem height ranging from 20 to $60 \mathrm{~cm}$, and moreover, with one of the biggest and conspicuous flowers of all European orchids. One or two flowers per stem consist of three purple-brown sepals, two similarly colored petals, and a petal called labellum, which is yellow and shoe shaped to form a trap. The pollen consists of single pollen grains contained in a sticky smear. Seeds are with a size of $1.2 \times 0.3 \mathrm{~mm}$ among the biggest of temperate orchids and are produced in high numbers (6000-16,000; Kull 1999). The plant propagates also vegetatively with horizontal rhizomes, building patches with many ramets belonging to one or several clones (Brzosko et al. 2002). The successful pollination of $C$. calceolus depends on small insects temporarily trapped in the labellum and leaving the slippery cavern through a posterior exit opening, thereby depositing pollen imported from other flowers on the stigma and collecting pollen from the anthers (Nilsson 1979, and references therein).

Cypripedium calceolus is regarded as a rare plant and is protected by Annex II of the Habitats Directive of the European Commission. In the IUCN Red List, however, it has 
received the status "Least Concern" (IUCN 2015) and is regarded as "widespread and the trend of the population is stable. Some of the subpopulations in parts of its range are declining due [to] numerous threats, especially collection by enthusiasts, but most of them are stable or even increasing in other parts due to conservation measures that have been implemented."

\section{Study sites}

Investigations were conducted in the German Limestone Alps. The four study sites are in an area within 4-19 km distance, three of them within the National Park (NP) Berchtesgaden (see Fig. 1). The region is situated on the northwestern slopes of the Alps in the transition zone of atlantic and continental climate, cool-temperate and humid, with mean annual temperatures above $10^{\circ} \mathrm{C}$ and annual precipitation of $1500 \mathrm{~mm}$ in the lower elevations and mean annual temperatures below $0{ }^{\circ} \mathrm{C}$ and precipitation of up to $2600 \mathrm{~mm}$ in the higher elevations. Precipitation has its seasonal minimum in April and its maximum in July (Marke et al. 2013)—with the flowering season of C. calceolus being in between.

The lowest study population Bartholomew is a peninsular on western shore of the Königssee in the NP Berchtesgaden, $605 \mathrm{~m}$ a.s.l. It is characterized by very light spruce (Picea abies) and willow (Salix spp.) forests along the lake shore, with patches of wet grassland in between. The forest is denser further inland, with a higher abundance of spruce. Almbach is a narrow gorge in the Untersberg massif, $760 \mathrm{~m}$ a.s.l. A few C. calceolus plants are found close to the creek, which is surrounded by a spruce forest. Königsbach is part of the extensive alpine pastures east above the Königssee in the NP Berchtesgaden, $1200 \mathrm{~m}$ above sea level. $C$. calceolus is found in the steep spruce forest nearby and in the grazed less dense forest along a creek. Wimbach is the valley between the two mountain massifs Watzmann and Hochkalter. It is characterized by huge rubble streams and brittle dolomite slopes surrounding it. In the upper part, at the altitude of $1450 \mathrm{~m}$ where $C$. calceolus grows, the pine forest (Pinus mugo) has a low density with much undergrowth.

\section{Scent collection}

Thermal desorption (TD) samples of Cypripedium calceolus flowers were collected to test for a population effect in scent emission. Experiments were carried out at the end of May 2013 (Almbach) and between May 22 and June 10, 2014 (three other sites). Floral volatiles were collected in situ during daytime from first-day flowers (but from unknown age in Almbach due to logistic issues), using dynamic headspace methods (Dötterl et al. 2005). In total,
60 samples from different individuals (patches) were collected: 14 in Bartholomew, 5 in Almbach, 21 in Königsbach, and 20 in Wimbach. In Almbach, where samples were collected first, flowers were enclosed in polyester oven bags $\left(10 \times 15 \mathrm{~cm}\right.$; Toppits $\mathrm{R}^{\odot}$, Germany) for 5-30 min to allow accumulation of floral scent. As analyses of these samples (see below) revealed that a bagging time of $5 \mathrm{~min}$ is enough to obtain good results (Dötterl et al., unpublished data), an accumulation time of 5 min was used for all samples collected from the other populations. Following the accumulation, volatiles were trapped by pulling the air from the bag through small adsorbent tubes (Varian Inc. ChromatoProbe quartz micro vials; length: $15 \mathrm{~mm}$, inner diameter: $2 \mathrm{~mm}$ ) for 3 min using a membrane pump (G12/01 EB, Rietschle Thomas Inc., Puchheim, Germany; flow rate: $200 \mathrm{ml} / \mathrm{min}$ ). The tubes contained $1.5 \mathrm{mg}$ Tenax-TA (mesh 60-80) and $1.5 \mathrm{mg}$ Carbotrap B (mesh 20-40; both Supelco) fixed by glass wool plugs (Heiduk et al. 2015; Mitchell et al. 2015). Samples of non-flowering stems, leaves, and ambient air were collected from each population as negative controls (11 in total).

To obtain solvent acetone (S) samples for electrophysiological analyses, two samples were collected in 2013. One sample (S1) was collected for $2 \mathrm{~h}$ from five enclosed flowers of a single patch of $C$. calceolus at Almbach, the other (S2) for $30 \mathrm{~min}$ following an accumulation time of $105 \mathrm{~min}$ from six enclosed flowers of a single patch at Königsbach. Such differences in accumulation and collection time were shown to produce very similar results as known from studies with other plants (Dötterl, unpublished data). The scent was trapped in larger adsorbent tubes (glass capillaries; length: $8 \mathrm{~cm}$, inner diameter: $2.5 \mathrm{~mm}$ ) filled with $15 \mathrm{mg}$ Tenax-TA (mesh 60-80) and $15 \mathrm{mg}$ Carbotrap B (mesh 20-40) and a flow rate of $100 \mathrm{ml} / \mathrm{min}$. The volatiles trapped on an adsorbent tube were eluted with $70 \mu \mathrm{l}$ of acetone (Rotisolv, Roth, Germany) and stored at $-20^{\circ} \mathrm{C}$ until using them for the measurements.

\section{Scent analysis}

The small adsorbent tubes with the trapped volatiles were analyzed by GC/MS using an automatic thermal desorption (TD) system (TD-20, Shimadzu, Japan) coupled to a Shimadzu GC/MS-QP2010 Ultra equipped with a ZB-5 fused silica column (5\% phenyl polysiloxane; $60 \mathrm{~m}$, i.d. $0.25 \mathrm{~mm}$, film thickness $0.25 \mu \mathrm{m}$, Phenomenex), the same as described by Heiduk et al. (2015). The samples were run with a split ratio of 1:1 and a consistent helium carrier gas flow of $1.5 \mathrm{ml} / \mathrm{min}$. The $\mathrm{GC}$ oven temperature started at $40^{\circ} \mathrm{C}$, then increased by $6^{\circ} \mathrm{C} / \mathrm{min}$ to $250^{\circ} \mathrm{C}$ and was held for $1 \mathrm{~min}$. The MS interface worked at $250^{\circ} \mathrm{C}$. Mass spectra were taken at $70 \mathrm{eV}$ (EI mode) from $\mathrm{m} / \mathrm{z} 30$ to 350 . GC/ 


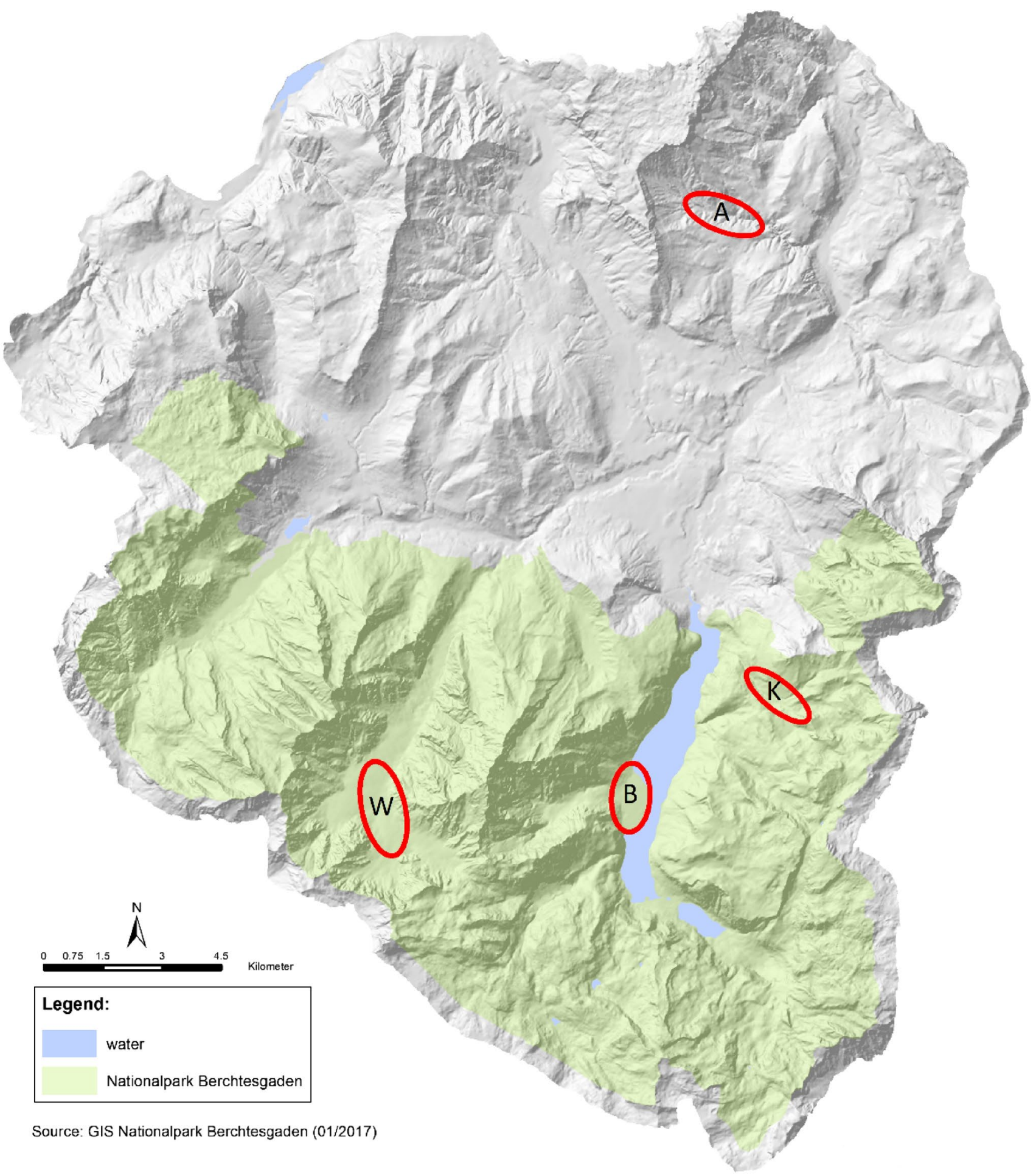

Fig. 1 Location of study sites in the limestone mountains of Berchtesgaden. A Almbach (760 m a.s.1.), $B$ Bartholomew (605 m a.s.1.), $K$ Königsbach (1200 $\mathrm{m}$ a.s.1.), $W$ Wimbach (1450 m a.s.1.)

MS data were processed using the GCMSolution package, Version 4.11 (Shimadzu Corporation 1999-2013).

To identify EAD-active compounds (see below), S samples were analyzed by GC/MS using a Shimadzu
GCMS-QP2010 Ultra equipped with an AOC-20i auto injector (Shimadzu, Tokyo, Japan) and again a ZB-5 fused silica column (5\% phenyl polysiloxane; length: $30 \mathrm{~m}$, inner diameter: $0.32 \mathrm{~mm}$, film thickness: $0.25 \mu \mathrm{m}$, Phenomenex) 
as described by Heiduk et al. $(2015,2016) .1 .0 \mu \mathrm{l}$ of the samples was injected at $220^{\circ} \mathrm{C}$ with a split ratio $1: 1$, and the column flow (carrier gas: helium) was set at $3 \mathrm{ml} / \mathrm{min}$. The GC oven temperature was held at $40^{\circ} \mathrm{C}$ for $1 \mathrm{~min}$, then increased by $10^{\circ} \mathrm{C} / \mathrm{min}$ to $220^{\circ} \mathrm{C}$, and held for $2 \mathrm{~min}$. The MS interface worked at $220^{\circ} \mathrm{C}$. Mass spectra were again taken at $70 \mathrm{eV}$ (in EI mode) from m/z 30 to 350 and data processed as described above.

Identification of the compounds was carried out using the ADAMS, ESSENTIALOILS-23P, FFNSC 2, and W9N11 databases, as well as a database generated from synthetic standards available in the Plant Ecology lab of the University of Salzburg. Based on the compounds detected in C. calceolus, a library was generated and used for automated quantification of samples (parameter settings: minimum similarity: $80 \%$, allowance of retention index shift: \pm 5 ). Compounds were only included in the study if peak areas in flower samples were at least five times larger than from the associated green leaf and ambient air controls.

Total scent emission (based on TD samples) was estimated by injecting known amounts of monoterpenes, aromatics, and aliphatics (added to small adsorbent tubes). The mean response of these compounds (mean peak area) was used to determine the total amount of scent in C. calceolus (Dötterl et al. 2005).

\section{Flower visitor and pollinator observation, collection, and identification}

In the flowering seasons of 2014-2016, on warm and sunny days, where pollinators of $C$. calceolus have been shown to be most active (Nilsson 1979, own observations), one to four persons went from plant to plant and inspected the flowers for trapped insects in three of the study populations (Bartholomew, Königsbach and Wimbach). Observation time accumulated to about $80 \mathrm{~h}$ in Bartholomew, $40 \mathrm{~h}$ in Königsbach, and $90 \mathrm{~h}$ in Wimbach. If insects were found, a perforated transparent plastic bag was put over the flower and the exit mode of the insect-either through the posterior exit opening or back out through the labellum mouthwas observed. The duration of this observation varied vastly, from seconds to hours. After exiting, the insects were captured in the bag and either collected or imaged ( 25 specimens, for which we assumed to belong to a species we collected before at least once) for determination purposes. Immediately after capturing, insects which left through the posterior exit were examined for pollen smear on their back. For imaging, insects were anesthetized by exposure to $\mathrm{CO}_{2}$, photographed with a digital camera (Canon S100) together with a scale, and then released. We did not collect all insects exiting a flower for nature conservation reasons. Some insects did not manage to get out of the labellum once trapped and died inside the labellum. Such insects were collected after dying. Insects found already dead in the labella were also collected.

All insects found inside the labellum of the flower were categorized as flower visitors. Very small insects, which obviously could not act as pollinators, where excluded from analyses. The subset of flower visitors, which left through the posterior exit and collected pollen smear on their back, are potential pollen vectors and were categorized as pollinators.

Bees were determined using Amiet (1996), Amiet et al. (2001, 2004, 2007, 2010), and Gokcezade et al. (2010), the syrphid flies using Speight and Sarthou (2014).

\section{Electrophysiological experiments}

In our preliminary electroantennographic analyses, we tested specimen of four species found as flower visitors/ pollinators in the present study [bees: Andrena bicolor (1 female individual), A. haemorrhoa (3f), Lasioglossum calceatum/albipes (2f); flies: Platycheirus albimanus (2, male and female)] and additionally a species [A. cineraria (1f)], which very likely occurs in the study area (Scheuchl and Willner 2016) and was found as flower visitor of C. calceolus in previous studies (Antonelli et al. 2009; Erneberg and Holm 1999), but not in present one. Both antennae were tested in consecutive runs. Compounds with an obvious response in at least one run per individual were treated as EAD active.

The analyses were performed with an Agilent 7890A (Santa Clara, California, USA) gas chromatograph as described by Heiduk et al. (2015, 2016). The GC was equipped with a flame ionization detector (FID) and an EAD setup (heated transfer line, 2-channel USB acquisition controller) provided by Syntech (Kirchzarten, Germany). For each run, an acetone scent sample was injected in splitless mode (injector temperature: $250^{\circ} \mathrm{C}$; oven temperature: $40^{\circ} \mathrm{C}$ ). The oven heated by $10^{\circ} \mathrm{C} / \mathrm{min}$ to $220^{\circ} \mathrm{C}$. The GC was equipped with a ZB-5 column for analysis (5\% phenyl polysiloxane; length: $30 \mathrm{~m}$, inner diameter: $0.32 \mathrm{~mm}$, film thickness: $0.25 \mu \mathrm{m}$, Phenomenex). The column was split at the end by a $\mu$ Flow splitter (Gerstel, Mühlheim, Germany; nitrogen was used as make-up gas) into two deactivated capillaries, one (length: $2 \mathrm{~m}$, inner diameter: $0.15 \mathrm{~mm}$ ) leading to the FID setup, the other (length: $1 \mathrm{~m}$, inner diameter: $0.2 \mathrm{~mm}$ ) leading to the EAD setup. The outlet of the EAD was placed in a cleaned, humidified air flow directed over the antenna.

The tested insects were either collected from flowers of C. calceolus (L. calceatum and P. albimanus) or from the Botanical Garden of the University of Salzburg (only bees). The species collected in the Botanical Garden are all very widespread and not known to occur as different ecotypes (Scheuchl and Willner 2016), and we thus assumed that 
specimen collected few $\mathrm{km}$ from the populations of $C$. calceolus away responded similarly to the floral scents. All specimens were anesthetized with $\mathrm{CO}_{2}$ before cutting off their antennae or head (syrphids). Also, the very tip of bee antennae was cut off. The antenna or head was mounted between two glass micropipettes filled with insect Ringer's solution $(8.0 \mathrm{~g} / \mathrm{l} \mathrm{NaCl}, 0.4 \mathrm{~g} / \mathrm{l} \mathrm{KCl}, 4.0 \mathrm{~g} / \mathrm{l} \mathrm{CaCl}$ ), connected to silver wires. The basal part of the antenna or the caudal side of the head was connected to the reference electrode, and the recording electrode was placed in contact with the tip of the antenna.

\section{Statistical analysis}

\section{Flower scent}

Quantitative differences in absolute total amount of scent among populations were tested with Kruskal-Wallis tests (R kruskal.test \{stats $\}$ version 3.1.2) and post hoc tests with pairwise comparisons using Tukey and Kramer (Nemenyi) test for independent samples ( $\mathrm{R}$ posthoc.kruskal.nemenyi. test $\{$ PMCMR $\}$ version 4.1).

For analyses of qualitative differences in flower scent among populations, we calculated the qualitative Sørensen index to determine pairwise qualitative similarities among the individual samples. Based on the obtained similarity matrices, we performed analyses of similarities (ANOSIM, 10,000 permutations) to assess differences in scent among populations, and PERMDISP (Anderson et al. 2008) to test for differences in dispersion among populations $(10,000$ permutations), both with Primer 6.1.16 (Clarke and Gorley 2006).

For analyses of semi-quantitative (i.e., relative amounts of scent components within a flower) differences in scent among sites, we calculated the Bray-Curtis similarity index using Primer 6.1.15 to assess pairwise semi-quantitative similarities among the individual samples, and performed an ANOSIM (10,000 permutations) based on the obtained similarity matrix. Semi-quantitative instead of quantitative data were used because the total amount of trapped volatiles varied among as well as within sites. Non-metric multidimensional scaling (NMDS), based on the Bray-Curtis similarities, was used to graphically display the semi-quantitative differences in flower scents among sites. The stress value indicates how well the two-dimensional plot represents relationships among samples in multidimensional space. Stress values $<0.15$ indicate a good fit (Smith 2003). A SIMPER analysis was used to determine the compounds most responsible for variation in scent among populations, and PERMDISP was used to test for differences in dispersion of semi-quantitative floral scent data among populations (10,000 permutations), both using Primer 6.1.16.
For correlation analyses between most abundant floral compounds, we used Pearson's rho rank correlation coefficient (R rcorr \{Hmisc $\}$ version 3.17-1).

\section{Flower visitors and pollinators}

Fisher exact test was used to test for different distributions of flower visitors and pollinators among populations, on species level (R fisher.test \{stats\} version 3.1.2). For post hoc analysis standard Bonferroni correction for multiple tests was applied.

\section{Results}

\section{Composition of flower scent}

The flower scent of $C$. calceolus from the four populations comprised in total 71 compounds, most of which were (tentatively) identified (Table 1). Terpenoids (26 substances), aliphatic (20), and aromatic (14) compounds were most numerous and these three compound classes were also the most abundant ones (aliphatic compounds: 53\%; terpenoids: $41 \%$; aromatic compounds: $6 \%$ ). C5-branched chain compounds, nitrogen-containing, and unknown substances were less numerous and contributed together less than a half percent to the total amount of scent emitted. Seven compounds were found in all samples: benzaldehyde, linalool, heptyl acetate, hexyl acetate, octyl acetate, (Z)-3-hexenyl acetate, and 1-octanol. The compounds $(E)$-linalool oxide furanoid and heptanal were also frequently found (>98\% of samples), whereas the other compounds were less frequent. Linalool and octyl acetate were overall by far the most abundant compounds, although both substances varied strongly in relative amount among samples (linalool: 1-73\%; octyl acetate: 1-62\%). Samples with high relative amounts of linalool had small amounts of octyl acetate and vice versa (see Fig. 2). The two samples with small relative amounts of both linalool and octyl acetate ( $\leq 25 \%$ each) had benzaldehyde as most abundant compound ( $>29 \%$ ).

\section{Variations in scent among populations}

\section{Quantitative data}

The total amount of scent trapped per flower and minute differed among populations (Table 1; Kruskal-Wallis test $H(3 ; 57)=15.1 ; P<0.01)$. Post hoc tests revealed that flowers in Königsbach released a smaller amount of scent than flowers in Bartholomew and Wimbach. Almbach did not differ in the total amount of scent released from the other populations, though the median amount was similar small as in Königsbach. 
Table 1 Occurrence, total absolute, and relative amount of scent found in 60 flower scent samples of the four populations Bartholomew (605 m.a.s.l.; 14 samples), Almbach (760 m, 5 samples), Königsbach (1200 m, 21 samples), and Wimbach (1450 m, 20 samples)

\begin{tabular}{|c|c|c|c|c|c|c|c|c|c|}
\hline \multirow[t]{3}{*}{$\mathrm{RI}^{\mathrm{a}}$} & \multirow[t]{3}{*}{ Compound $^{\mathrm{b}}$} & \multicolumn{4}{|l|}{ Occurence } & \multicolumn{4}{|c|}{ Relative amount (\%) } \\
\hline & & \multicolumn{4}{|l|}{$\%$ of samples } & \multicolumn{4}{|c|}{ Median (minimum-maximum) } \\
\hline & & Bartholomew & Almbach & Königsbach & Wimbach & Bartholomew & Almbach & Königsbach & Wimbach \\
\hline \multicolumn{10}{|c|}{ Aliphatic compounds } \\
\hline 855 & (Z)-3-Hexen-1-ol ${ }^{\mathrm{d}}$ & 86 & 0 & 67 & 75 & $*(0-4)$ & $0(0-0)$ & $1(0-4)$ & $1(0-2)$ \\
\hline 866 & 1-Hexanol ${ }^{\mathrm{d}}$ & 100 & 0 & 95 & 85 & $*(*-1)$ & $0(0-0)$ & $1(0-1)$ & $*(0-1)$ \\
\hline 902 & Heptanal $^{\mathrm{d}}$ & 100 & 100 & 100 & 95 & $1(*-10)$ & $1(*-2)$ & $2(*-3)$ & $1(0-4)$ \\
\hline 913 & Pentyl acetate & 86 & 20 & 62 & 80 & $*(0-1)$ & $0(0-*)$ & $*(0-*)$ & $*(0-*)$ \\
\hline 1006 & (Z)-3-Hexenyl acetate ${ }^{\mathrm{d}}$ & 100 & 100 & 100 & 100 & $2(1-11)$ & $1(1-17)$ & $1(*-12)$ & $2(1-12)$ \\
\hline 1011 & Hexyl acetate ${ }^{d}$ & 100 & 100 & 100 & 100 & $3(2-9)$ & $3(2-6)$ & $3(1-9)$ & $2(1-4)$ \\
\hline 1070 & 1-Octanol ${ }^{\mathrm{d}}$ & 100 & 100 & 100 & 100 & $1(*-3)$ & $1(*-6)$ & $2(1-8)$ & $1(*-4)$ \\
\hline 1111 & Heptyl acetate ${ }^{\mathrm{d}}$ & 100 & 100 & 100 & 100 & $1(1-2)$ & $1(1-1)$ & $2(1-5)$ & $1(1-6)$ \\
\hline 1122 & 3-Octyl acetate & 14 & 0 & 0 & 5 & $0(0-*)$ & $0(0-0)$ & $0(0-0)$ & $0(0-*)$ \\
\hline 1129 & Octyl formate & 21 & 0 & 67 & 15 & $0(0-*)$ & $0(0-0)$ & $*(0-*)$ & $0(0-*)$ \\
\hline 1162 & Octanoic acid ${ }^{\mathrm{d}}$ & 93 & 20 & 67 & 75 & $*(0-1)$ & $0(0-*)$ & $*(0-2)$ & $*(0-2)$ \\
\hline 1200 & an Octenyl acetate & 50 & 20 & 43 & 70 & $*(0-*)$ & $0(0-*)$ & $0(0-*)$ & $*(0-*)$ \\
\hline 1210 & Octyl acetate ${ }^{\mathrm{d}}$ & 100 & 100 & 100 & 100 & $34(1-46)$ & $37(2-47)$ & $29(1-62)$ & $25(12-47)$ \\
\hline 1272 & 1-Decanol ${ }^{d}$ & 93 & 40 & 86 & 90 & $*(0-1)$ & $0(0-*)$ & $*(0-1)$ & $*(0-1)$ \\
\hline 1295 & (Z)-3-Nonenyl acetate & 100 & 40 & 100 & 95 & $*(*-1)$ & $0(0-1)$ & $*(*-1)$ & $*(0-1)$ \\
\hline 1309 & Nonyl acetate & 100 & 80 & 100 & 100 & $*(*-2)$ & $*(0-*)$ & $*(*-2)$ & $*(*-1)$ \\
\hline 1409 & Decyl acetate ${ }^{\mathrm{d}}$ & 100 & 80 & 95 & 100 & $9(*-17)$ & $1(0-11)$ & $3(0-19)$ & $8(1-19)$ \\
\hline 1475 & 1-Dodecanol ${ }^{\mathrm{d}}$ & 79 & 40 & 67 & 100 & $*(0-2)$ & $0(0-*)$ & $*(0-1)$ & $*(*-1)$ \\
\hline 1608 & Dodecyl acetate & 64 & 40 & 38 & 40 & $*(0-1)$ & $0(0-*)$ & $0(0-1)$ & $0(0-1)$ \\
\hline 1808 & Tetradecyl acetate $^{\mathrm{d}}$ & 14 & 20 & 10 & 0 & $0(0-*)$ & $0(0-*)$ & $0(0-*)$ & $0(0-0)$ \\
\hline \multicolumn{10}{|c|}{ Aromatic compounds } \\
\hline 966 & Benzaldehyde $^{\mathrm{d}}$ & 100 & 100 & 100 & 100 & $2(*-29)$ & $1(*-1)$ & $1(1-12)$ & $1(1-33)$ \\
\hline 1025 & 4-Methylanisole ${ }^{\mathrm{d}}$ & 57 & 60 & 14 & 85 & $*(0-*)$ & $*(0-*)$ & $0(0-1)$ & $*(0-1)$ \\
\hline 1037 & Benzyl alcohol $^{\mathrm{d}}$ & 93 & 80 & 52 & 65 & $*(0-6)$ & $*(0-3)$ & $*(0-6)$ & $*(0-9)$ \\
\hline 1048 & Phenylacetaldehyde ${ }^{\mathrm{d}}$ & 21 & 0 & 10 & 10 & $0(0-*)$ & $0(0-0)$ & $0(0-*)$ & $0(0-1)$ \\
\hline 1074 & $\mathrm{p}$-Cresol ${ }^{\mathrm{d}}$ & 14 & 60 & 5 & 25 & $0(0-2)$ & $1(0-2)$ & $0(0-1)$ & $0(0-1)$ \\
\hline 1082 & Benzyl formate & 14 & 40 & 10 & 15 & $0(0-*)$ & $0(0-*)$ & $0(0-*)$ & $0(0-*)$ \\
\hline 1120 & 2-Phenylethanol ${ }^{d}$ & 79 & 60 & 5 & 85 & $*(0-1)$ & $*(0-*)$ & $0(0-*)$ & $*(0-1)$ \\
\hline 1168 & Benzyl acetate $^{d}$ & 57 & 40 & 29 & 15 & $*(0-2)$ & $0(0-2)$ & $0(0-1)$ & $0(0-2)$ \\
\hline 1167 & 1,4-Dimethoxybenzene ${ }^{\mathrm{d}}$ & 0 & 100 & 0 & 15 & $0(0-0)$ & $*(*-*)$ & $0(0-0)$ & $*(0-*)$ \\
\hline 1182 & 2-Phenylethyl formate & 0 & 0 & 0 & 5 & $0(0-0)$ & $0(0-0)$ & $0(0-0)$ & $0(0-*)$ \\
\hline 1205 & Methyl salicylate $^{\mathrm{d}}$ & 21 & 0 & 0 & 0 & $0(0-1)$ & $0(0-0)$ & $0(0-0)$ & $0(0-0)$ \\
\hline 1262 & 2-Phenylethyl acetate ${ }^{\mathrm{d}}$ & 86 & 80 & 62 & 80 & $1(0-3)$ & $*(0-1)$ & $*(0-*)$ & $*(0-4)$ \\
\hline 1366 & Eugenol $^{\mathrm{d}}$ & 43 & 20 & 5 & 45 & $0(0-*)$ & $0(0-*)$ & $0(0-*)$ & $0(0-1)$ \\
\hline 1669 & $\begin{array}{l}\text { cf 1,4-Dimethylindanyl } \\
\text { acetate }\end{array}$ & 57 & 40 & 0 & 50 & $*(0-2)$ & $0(0-*)$ & $0(0-0)$ & $*(0-1)$ \\
\hline \multicolumn{10}{|c|}{ Terpenoids } \\
\hline 987 & $\begin{array}{l}\text { 6-Methyl-5-hepten- } \\
\text { 2-one }{ }^{\mathrm{d}}\end{array}$ & 93 & 100 & 95 & 95 & $1(0-3)$ & $3(1-6)$ & $3(0-9)$ & $2(0-5)$ \\
\hline 993 & $\beta$-Myrcene ${ }^{\mathrm{d}}$ & 36 & 60 & 0 & 50 & $0(0-1)$ & $*(0-3)$ & $0(0-0)$ & $*(0-2)$ \\
\hline 1018 & Pinocarvone $^{\mathrm{d}}$ & 86 & 0 & 38 & 5 & $*(0-*)$ & $0(0-0)$ & $0(0-*)$ & $0(0-1)$ \\
\hline 1037 & $\beta$-Phellandrene ${ }^{\mathrm{d}}$ & 0 & 0 & 5 & 15 & $0(0-0)$ & $0(0-0)$ & $0(0-*)$ & $0(0-*)$ \\
\hline 1039 & $(Z)-\beta$-Ocimene ${ }^{\mathrm{d}}$ & 7 & 40 & 10 & 15 & $0(0-*)$ & $0(0-1)$ & $0(0-*)$ & $0(0-*)$ \\
\hline 1045 & Lavender lactone & 14 & 20 & 48 & 50 & $0(0-1)$ & $0(0-1)$ & $0(0-4)$ & $*(0-2)$ \\
\hline 1050 & $(E)-\beta$-Ocimene ${ }^{\mathrm{d}}$ & 71 & 80 & 90 & 85 & $*(0-*)$ & $*(0-1)$ & $*(0-1)$ & $*(0-*)$ \\
\hline 1056 & (Z)-Arbusculone & 0 & 0 & 0 & 10 & $0(0-0)$ & $0(0-0)$ & $0(0-0)$ & $0(0-*)$ \\
\hline 1078 & $\begin{array}{l}\text { (Z)-Linalool oxide } \\
\text { furanoid }^{\mathrm{d}}\end{array}$ & 64 & 40 & 95 & 80 & $*(0-*)$ & $0(0-*)$ & $*(0-1)$ & $*(0-1)$ \\
\hline 1094 & $\begin{array}{l}\text { (E)-Linalool oxide } \\
\text { furanoid }^{\mathrm{d}}\end{array}$ & 100 & 100 & 100 & 95 & $1(*-2)$ & $1(*-2)$ & $1(*-4)$ & $1(0-3)$ \\
\hline 1103 & Linalool $^{\mathrm{d}}$ & 100 & 100 & 100 & 100 & $28(14-62)$ & $27(19-73)$ & $35(4-71)$ & $38(1-64)$ \\
\hline
\end{tabular}


Table 1 (continued)

\begin{tabular}{|c|c|c|c|c|c|c|c|c|c|}
\hline \multirow[t]{3}{*}{$\mathrm{RI}^{\mathrm{a}}$} & \multirow[t]{3}{*}{ Compound $^{\mathrm{b}}$} & \multicolumn{4}{|l|}{ Occurence } & \multicolumn{4}{|c|}{ Relative amount (\%) } \\
\hline & & \multicolumn{4}{|l|}{$\%$ of samples } & \multicolumn{4}{|c|}{ Median (minimum-maximum) } \\
\hline & & Bartholomew & Almbach & Königsbach & Wimbach & Bartholomew & Almbach & Königsbach & Wimbach \\
\hline 1132 & Allo-Ocimene $^{\mathrm{d}}$ & 43 & 0 & 29 & 35 & $0(0-*)$ & $0(0-0)$ & $0(0-*)$ & $0(0-*)$ \\
\hline 1137 & Epoxy-oxoisophorone $^{\mathrm{d}}$ & 14 & 0 & 0 & 5 & $0(0-*)$ & $0(0-0)$ & $0(0-0)$ & $0(0-*)$ \\
\hline 1150 & 4-Oxoisophorone ${ }^{\mathrm{d}}$ & 64 & 100 & 52 & 80 & $2(0-5)$ & $4(1-6)$ & $1(0-5)$ & $2(0-8)$ \\
\hline 1180 & $\begin{array}{l}\text { (Z)-Linalool oxide } \\
\text { pyranoid }^{\mathrm{d}}\end{array}$ & 100 & 80 & 95 & 95 & $*(*-*)$ & $*(0-*)$ & $*(0-*)$ & $*(0-*)$ \\
\hline $1211-1231$ & Lilac alcohol A-D ${ }^{d}$ & 57 & 0 & 43 & 85 & $*(0-*)$ & $0(0-0)$ & $0(0-*)$ & $*(0-1)$ \\
\hline 1233 & Nerol $^{\mathrm{d}}$ & 14 & 0 & 0 & 10 & $0(0-*)$ & $0(0-0)$ & $0(0-0)$ & $0(0-*)$ \\
\hline 1257 & Geraniol $^{\mathrm{d}}$ & 14 & 20 & 0 & 30 & $0(0-*)$ & $0(0-*)$ & $0(0-0)$ & $0(0-*)$ \\
\hline 1292 & $\begin{array}{r}(E) \text {-Linalool oxide } \\
\text { acetate pyranoid }\end{array}$ & 43 & 20 & 5 & 50 & $0(0-*)$ & $0(0-*)$ & $0(0-*)$ & $*(0-*)$ \\
\hline 1384 & Geranyl acetate $^{\mathrm{d}}$ & 7 & 0 & 0 & 5 & $0(0-*)$ & $0(0-0)$ & $0(0-0)$ & $0(0-*)$ \\
\hline 1458 & Geranyl acetone $^{\mathrm{d}}$ & 93 & 60 & 100 & 100 & $*(0-1)$ & $*(0-*)$ & $*(*-*)$ & $*(*-1)$ \\
\hline 1462 & (E)- $\beta$-Farnesene & 14 & 0 & 5 & 30 & $0(0-*)$ & $0(0-0)$ & $0(0-*)$ & $0(0-*)$ \\
\hline 1498 & $(Z, E)-\alpha-$ Farnesene & 21 & 0 & 0 & 15 & $0(0-*)$ & $0(0-0)$ & $0(0-0)$ & $0(0-*)$ \\
\hline 1513 & $(E, E)-\alpha$-Farnesene ${ }^{\mathrm{d}}$ & 43 & 60 & 48 & 60 & $0(0-1)$ & $*(0-1)$ & $0(0-1)$ & $*(0-3)$ \\
\hline $1348-1363$ & $\begin{array}{l}\text { Lilac alcohol formate } \\
\text { A-D }\end{array}$ & 93 & 20 & 81 & 95 & $*(0-1)$ & $0(0-*)$ & $*(0-1)$ & $*(0-1)$ \\
\hline 1571 & $(E)-$ Nerolidol $^{\mathrm{d}}$ & 14 & 40 & 0 & 0 & $*(0-*)$ & $*(*-*)$ & $0(0-0)$ & $0(0-0)$ \\
\hline \multicolumn{10}{|c|}{ C5-branched chain compounds } \\
\hline 876 & Isoamyl acetate $^{\mathrm{d}}$ & 21 & 0 & 0 & 0 & $0(0-*)$ & $0(0-0)$ & $0(0-0)$ & $0(0-0)$ \\
\hline \multicolumn{10}{|c|}{ Nitrogen-containing compounds } \\
\hline 1305 & Indole $^{d}$ & 21 & 0 & 14 & 10 & $0(0-*)$ & $0(0-0)$ & $0(0-*)$ & $0(0-*)$ \\
\hline \multicolumn{10}{|l|}{ Unknowns } \\
\hline & Unknowns $^{\mathrm{c}(9 \text { substances) }}$ & $31^{9}$ & $0^{\circ}$ & $4^{4}$ & $23^{7}$ & $*(0-*)$ & $0(0-0)$ & $0(0-*)$ & $*(0-*)$ \\
\hline \multicolumn{6}{|c|}{ Total absolute amount (ng) } & $156(34-652)$ & $52(28-280)$ & $61(31-179)$ & $134(42-337)$ \\
\hline
\end{tabular}

*Values $>0$ and $<0.5 \%$

${ }^{a}$ Kovats retention index

${ }^{\mathrm{b}}$ Compounds within classes are ordered according to Kovats retention index

${ }^{c}$ Unknowns are pooled with the superscript digit giving the number of pooled compounds

${ }^{\mathrm{d}}$ Compound identification verified through authentic standard

\section{Qualitative data}

In Bartholomew, 62 compounds were detected, in Wimbach 60, in Königsbach 48, and in Almbach 41, with 37 compounds found at all four study sites. Overall, the spectrum of compounds differed among populations (ANOSIM: $\left.R_{3: 56}=0.424 ; P<0.001\right)$ and these differences cannot be explained by differences in dispersion among populations (PERMDISP: $F_{3,56}=2.96, P=0.09$ ). Post hoc analyses showed that all populations differed from each other $(R>0.16 ; P<0.02)$ and released population-specific scents. Differences between Bartholomew and Wimbach were least pronounced $(R=0.16 ; P=0.01)$ and effects were stronger between all other pairs of populations $(R>0.43 ; P<0.001)$.

\section{Semi-quantitative data}

The relative amount of scent differed among populations

(Fig. 3; ANOSIM: $R_{3 ; 56}=0.134 ; P=0.002$ ) and these differences cannot be explained by differences in dispersion among populations (PERMDISP: $F_{3,56}=1.27$, $P=0.39$ ). Post hoc analyses showed that Wimbach differed from both Königsbach $\left(R_{3: 56}=0.124, P=0.004\right)$ and Almbach $\left(R_{3: 56}=0.363, P=0.018\right)$. Simper analyses revealed that these differences were mainly due to the most abundant compounds linalool and octyl acetate, which together explained more than $50 \%$ of differences among Wimbach and Königsbach, and Wimbach and Almbach (Table 1). Other pairwise comparisons among populations revealed non-significant test outcomes $\left(R_{3 ; 56}<0.21 ; P>0.05\right)$.

\section{Flower visitors and pollinators}

\section{Flower visitors}

We recorded 120 insects in the labellum of $C$. calceolus at three of the four study sites, all of them bees and syrphid flies, except a single sawfly (see Table 2). All visitors were 
Fig. 2 Relative amount of octyl acetate plotted against linalool. The trend line is also given (Pearson correlation: $\rho=-0.82$, $P<0.001, n=60)$. The total amount of scent of the sample is indicated by the size of the symbol, the population origin by its color

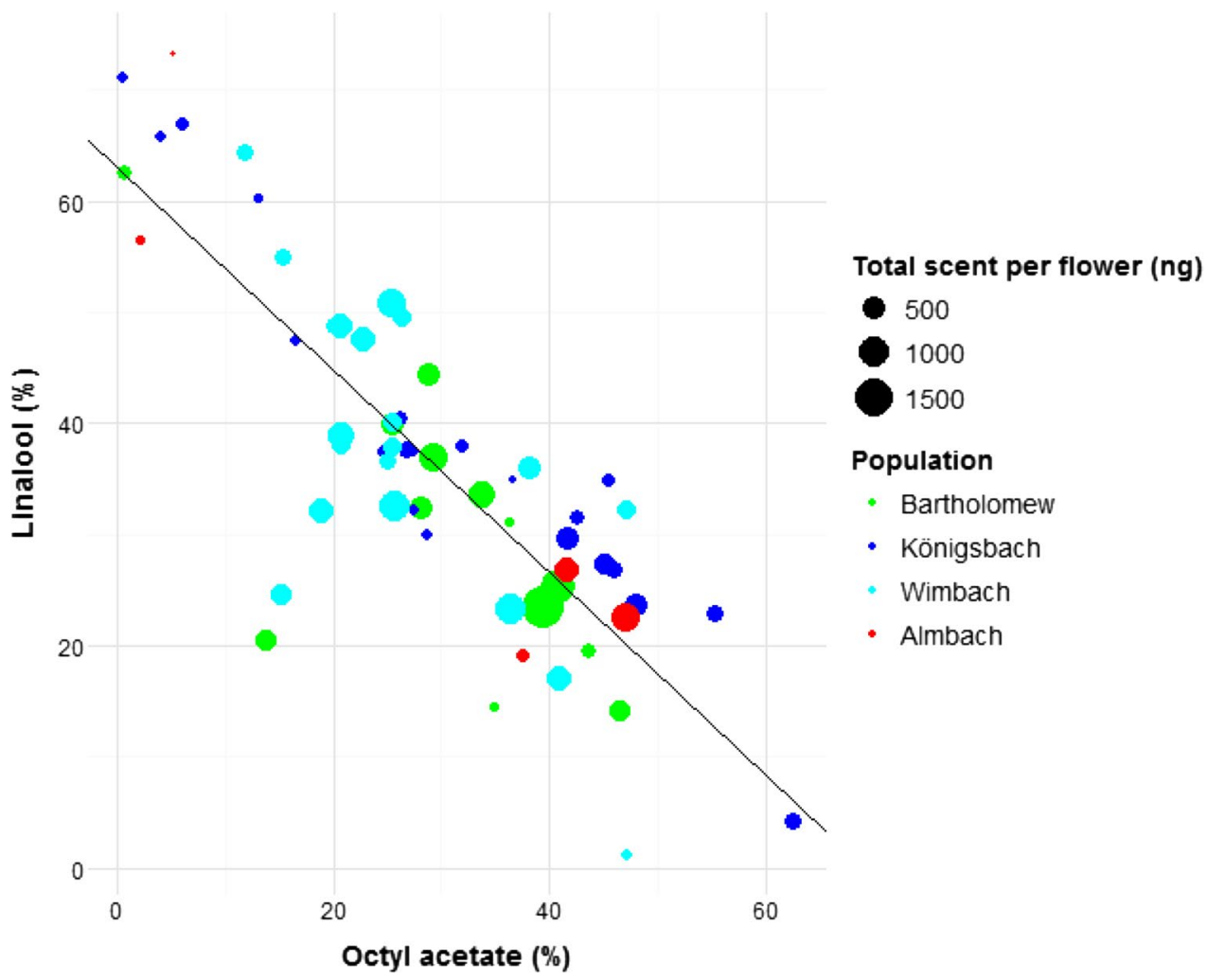

Fig. 3 Non-metric multidimensional scaling (NMDS) used to visualize semi-quantitative similarities among the single scent samples collected from four different populations. This ordination is based on pairwise Bray-Curtis similarities. Compounds most responsible for ordination of samples as indicated by a SIMPER analysis are also plotted

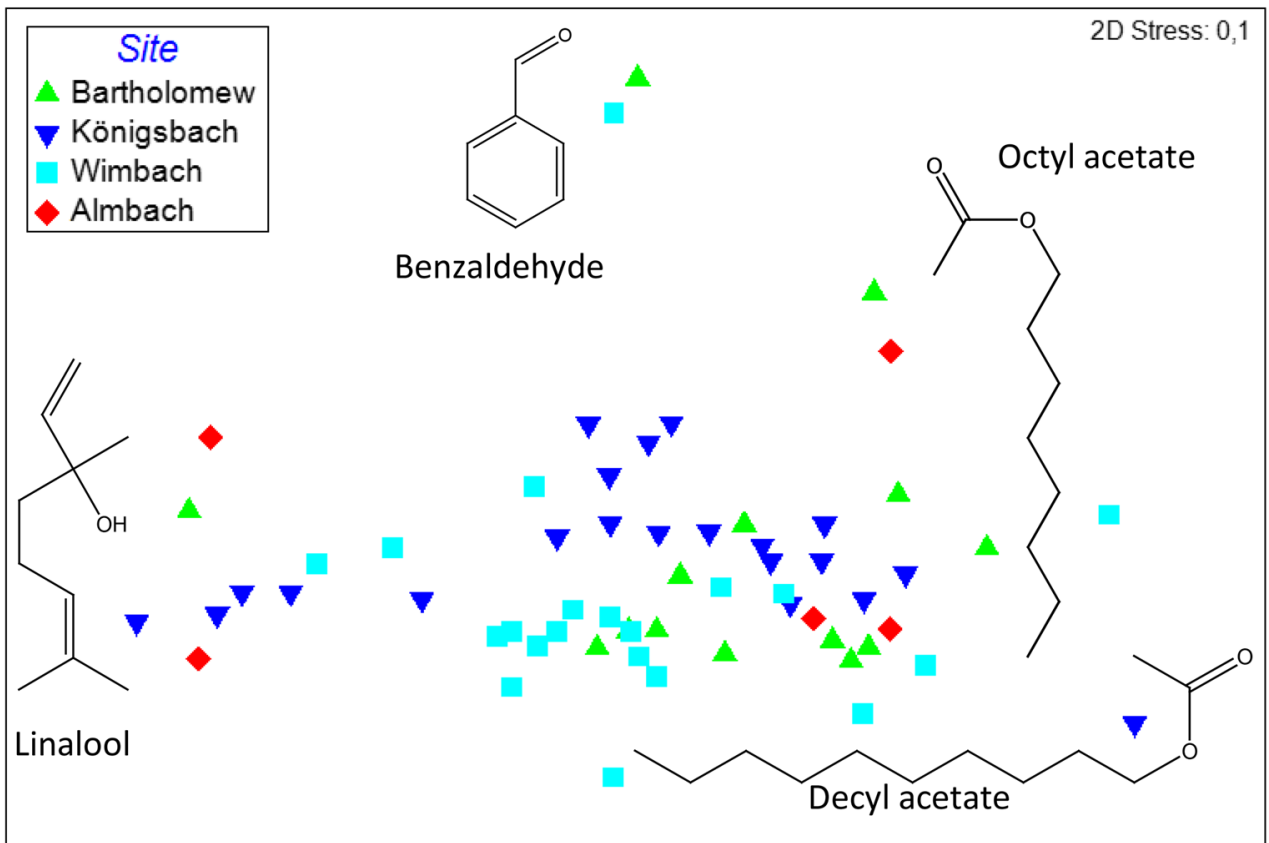

females, except for two Nomada panzeri and one Andrena jacobi bee, and an Eristalis rupium fly. Most numerous were bees of the genera Lasioglossum (49 individuals; 5 species) and Andrena (16; 9), and Platycheirus flies (16; 3). The other 49 individuals were from 19 other genera and 25 species (see Table 2).
The distribution of flower visitor species and genera differed among the study sites (Fig. 4; Fisher's Exact Test; $P<0.01)$. Remarkable are on the one hand differences in the abundance of Lasioglossum, with $60 \%$ in Bartholomew and just 18 and $16 \%$ in Königsbach and Wimbach, respectively. Syrphid flies on the other hand 
Table 2 Number of individuals of flower visitor and pollinator species of C. calceolus observed at the three study sites

\begin{tabular}{|c|c|c|c|c|c|c|c|c|c|}
\hline \multirow[t]{2}{*}{ Species } & \multirow[t]{2}{*}{ Order } & \multicolumn{2}{|l|}{ All sites } & \multicolumn{2}{|c|}{ Bartholomew } & \multicolumn{2}{|c|}{ Königsbach } & \multicolumn{2}{|c|}{ Wimbach } \\
\hline & & Visitors & Pollinators & Visitors & Pollinators & Visitors & Pollinators & Visitors & Pollinators \\
\hline Andrena bicolor Fabricius & Hymenoptera & 1 & 1 & 1 & 1 & & & & \\
\hline Andrena fucata Smith* & & 1 & & & & 1 & & & \\
\hline Andrena haemorrhoa (Fabricius)* & & 3 & & 3 & & & & & \\
\hline Andrena helvola (Linnaeus)* & & 1 & & 1 & & & & & \\
\hline Andrena jacobi Perkins* & & 6 & 1 & 6 & 1 & & & & \\
\hline Andrena cf. lapponica Zetterstedt & & 1 & & 1 & & & & & \\
\hline Andrena rogenhoferi Morawitz & & 1 & & 1 & & & & & \\
\hline Andrena sp. 1 & & 1 & 1 & & & 1 & 1 & & \\
\hline Andrena sp. 2 & & 1 & & & & & & 1 & \\
\hline Apis mellifera Linnaeus* & & 1 & & & & 1 & & & \\
\hline Bombus sylvestris (Lepeletier) & & 1 & & & & 1 & & & \\
\hline Halictus rubicundus (Christ) & & 1 & 1 & & & & & 1 & 1 \\
\hline Halictus tumulorum (Linnaeus)* & & 1 & & & & 1 & & & \\
\hline Lasioglossum bavaricum (Blüthgen) & & 3 & 2 & & & & & 3 & 2 \\
\hline $\begin{array}{l}\text { Lasioglossum calceatum/albipes } \\
\text { (Scopoli/Fabricius)* }\end{array}$ & & 38 & 25 & 34 & 22 & 3 & 3 & 1 & \\
\hline Lasioglossum fulvicorne (Kirby)* & & 4 & 2 & 3 & 1 & & & 1 & 1 \\
\hline Lasioglossum leucozonium (Schrank) & & 3 & 2 & 2 & 1 & 1 & 1 & & \\
\hline Lasioglossum sp. & & 1 & & 1 & & & & & \\
\hline Nomada panzeri Lepeletier* & & 2 & 2 & 1 & 1 & & & 1 & 1 \\
\hline Osmia bicornis (Linnaeus) & & 1 & & 1 & & & & & \\
\hline Hoplocampa plagiata (Klug) & & 1 & 1 & & & & & 1 & 1 \\
\hline Cheilosia cf. variabilis (Panzer) & Diptera & 1 & & & & & & 1 & \\
\hline Cheilosia morio (Zetterstedt) & & 1 & & & & & & 1 & \\
\hline Dasysyrphus albostriatus (Fallen) & & 3 & & & & 3 & & & \\
\hline Dasysyrphus friuliensis (Van der Goot) & & 1 & & 1 & & & & & \\
\hline Dasysyrphus venustus (Meigen) & & 1 & & 1 & & & & & \\
\hline Episyrphus balteatus (De Geer) & & 1 & & 1 & & & & & \\
\hline Eristalis rupium Fabricius & & 1 & 1 & & & 1 & 1 & & \\
\hline Lapposyrphus lapponicus (Zetterstedt) & & 11 & & 6 & & & & 5 & \\
\hline $\begin{array}{l}\text { Melangyna cf. lasiophthalma (Zet- } \\
\text { terstedt) }\end{array}$ & & 1 & & 1 & & & & & \\
\hline Melanostoma certum Haarto \& Stahls & & 1 & & & & & & 1 & \\
\hline Melanostoma mellinum (Linnaeus) & & 1 & & & & & & 1 & \\
\hline Pipiza austriaca Meigen & & 2 & 2 & 2 & 2 & & & & \\
\hline Platycheirus albimanus (Fabricius) & & 12 & 2 & & & 8 & 2 & 4 & \\
\hline Platycheirus ambiguus (Fallen) & & 2 & & & & & & 2 & \\
\hline Platycheirus cf. scutatus (Meigen) & & 2 & & & & & & 2 & \\
\hline Rhingia campestris Meigen & & 1 & & & & 1 & & & \\
\hline Scaeva selenitica (Meigen) & & 1 & & & & & & 1 & \\
\hline Sphaerophoria scripta (Linnaeus) & & 1 & & & & & & 1 & \\
\hline Syrphidae (other) & & 1 & & & & & & 1 & \\
\hline Syrphus ribesii (Linnaeus) & & 1 & & & & & & 1 & \\
\hline Syrphus vitripennis Meigen & & 1 & & & & & & 1 & \\
\hline
\end{tabular}

Species identified as pollinators in the present study are printed in bold. Species known from literature as pollinators are marked with an asterisk $(*)$. Pollinating individuals are a subset of flower visiting individuals 


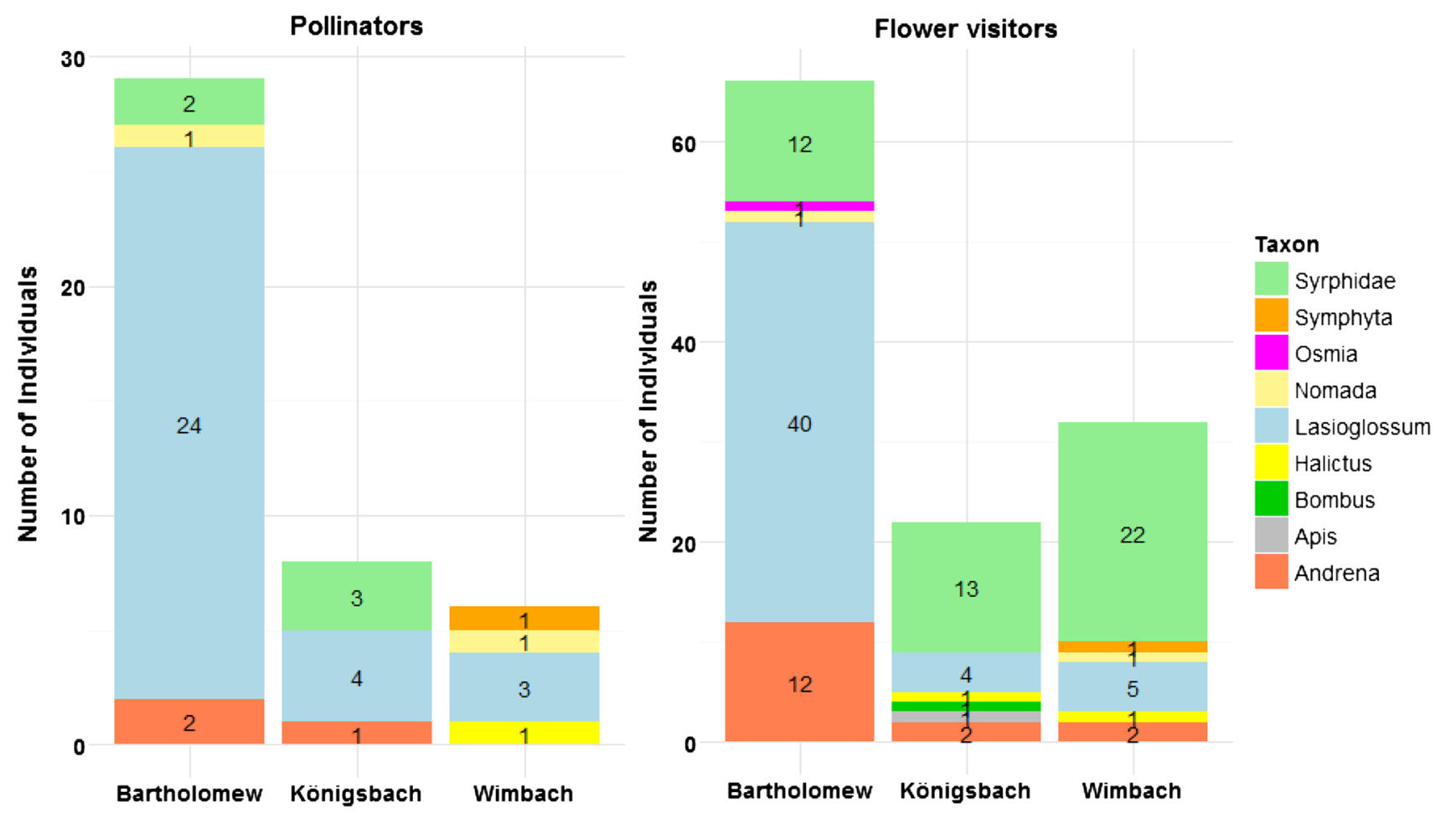

Fig. 4 Distribution of pollinator (left) and flower visitor (right) taxa at tree study sites. Lasioglossum was the most abundant single pollinator taxon at all sites and the most abundant flower visitor at Bartho-

were only abundant in Königsbach (59\%) and Wimbach (71\%) (see Fig. 4). The flowers in Bartholomew were visited by six Andrena species, compared to two and one in Königsbach and Wimbach, respectively. In contrast, 13 syrphid species were found as flower visitors in Wimbach, just six and four in Bartholomew and Königsbach, respectively. 36 of the 42 species were only found at one study site; one visitor species was found at all sites ( $L$. calceatum/albipes), three species were found both in Bartholomew and Wimbach, and one species each was shared between Königsbach and the other sites. Most species rich in flower visitors was Wimbach with 20 species, followed by Bartholomew with 18 and Königsbach with 11 species. Overall, in Bartholomew more Hymenoptera than Diptera individuals were trapped (55 vs. 12; $82 \%$ bees), and in Königsbach ( 9 vs. $13 ; 41 \%$ bees) and Wimbach ( 9 vs. $22 ; 29 \%$ bees and one sawfly) it was vice versa.

Bombus visited the flowers quite frequently, but often just landed on the labellum without entering. The few individuals, which entered the labellum, typically left it again after seconds. This was possible due to the large size of the bees with respect to the size of the labellum, which also hindered them to get in contact with the reproductive organs of the flower. One individual was found dead inside lomew, whereas syrphid flies were the most numerous visitors at the other two sites. Please note the different scales of the y-axes

a labellum, and only this individual was included in our list of flower visitors (Table 2, Fig. 4).

\section{Pollinators}

Forty three of the flower visitors were categorized as pollinators-six in Wimbach, eight in Königsbach, and 29 in Bartholomew. All pollinators were bees, except for two Platycheirus albimanus (Fig. 5), two Pipiza austriaca, and one Eristalis rupium syrphid fly/ies, and one sawfly (Hoplocampa plagiata; Symphyta). The pollinating bee genera were mostly Lasioglossum (31 specimens) (Fig. 4), followed by few individuals of Andrena (3), Nomada (2), and Halictus (1).

Lasioglossum bees were the most abundant pollinators at all sites, with a share of $83 \%$ in Bartholomew and $50 \%$ at the two other sites. Other pollinators in Bartholomew were syrphid flies and Andrena bees (7\% each) and one Nomada bee, in Königsbach syrphid flies (38\%) and Andrena bees (12\%). In Wimbach, various other genera (Halictus, Nomada, and the sawfly) completed the pollinator spectrum. The ratio Hymenoptera/Diptera was 27/2 (93\% bees) in Bartholomew, 5/3 (62\% bees) in Königsbach, and $6 / 0$ ( $86 \%$ bees and one sawfly) in Wimbach. Nine of the 13 pollinator species were found at just a single site 
Fig. 5 A female Platycheirus albimanus (Diptera, Syrphidae) visiting a flower of Cypripedium calceolus at Königsbach. A After landing on and before entering the labellum. B Passing the posterior exit. C With pollen smear (Po) on its head and thorax after leaving the flower. (Photos: Florian Etl, 2013)
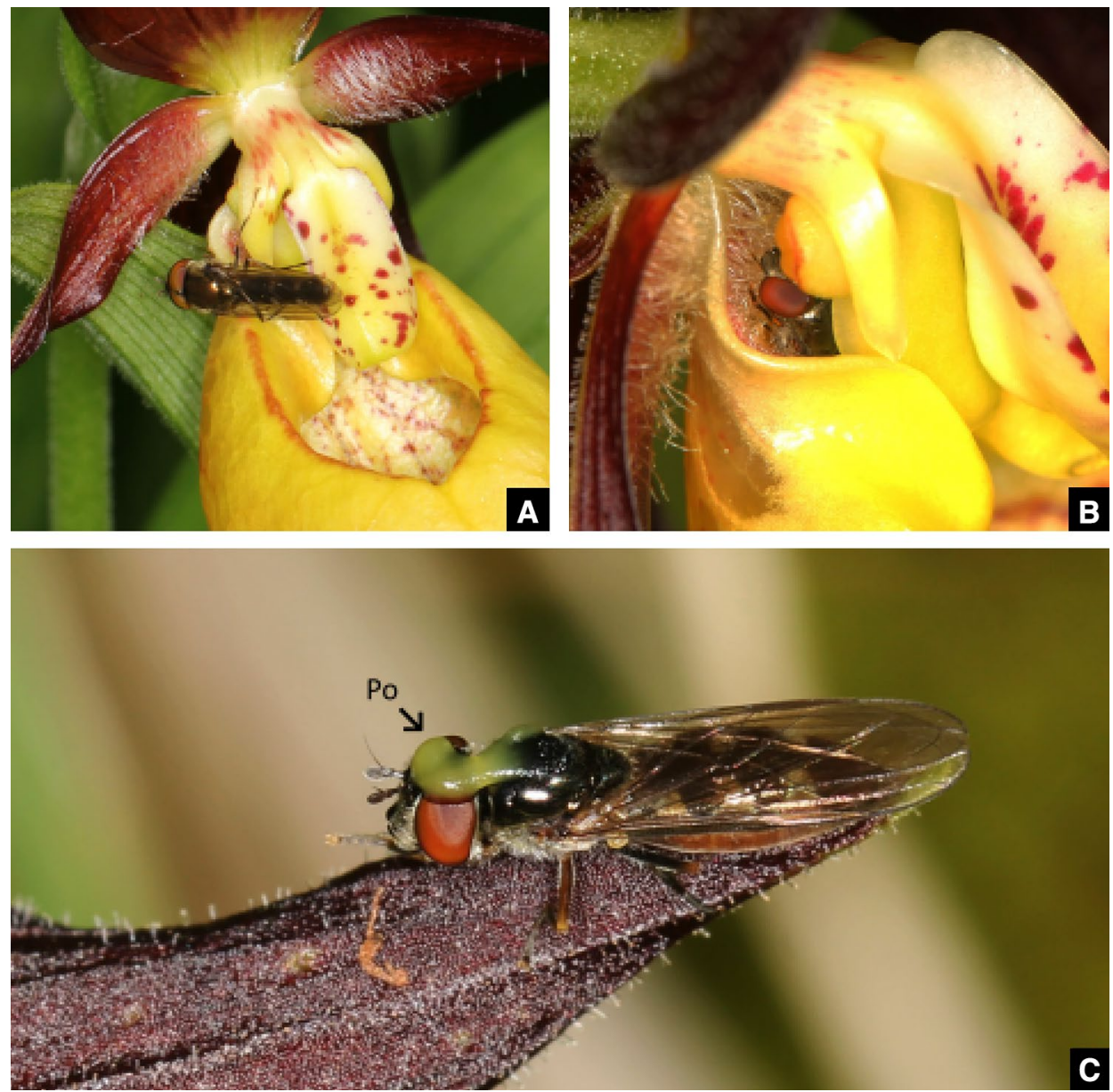

and two species each were shared between Bartholomew/ Königsbach and Bartholomew/Wimbach. In Bartholomew, seven pollinating species were found, five on each of the other sites. At each site, we found three pollinator species, which did not occur at any other site.

Statistical evaluation showed differences in the distribution of pollinators among the three sites based on species level (Fisher's Exact Test; $P<0.02$ ). In post hoc tests, the $P$ values were 0.029 (Bartholomew/Königsbach), 0.0007 (Bartholomew/Wimbach), and 0.049 (Königsbach/ Wimbach).

\section{Electroantennographic measurements}

The scent samples of $C$. calceolus contained 22 (S1) and 31 (S2) compounds, respectively, and antennae of tested insects responded to most of these compounds (Table 3; Figs. 6, 7). Nine of the compounds were sensed by all tested individuals: linalool, $(E)$-linalool oxide furanoid, 4-oxoisophorone, ( $Z$ )-3-nonenyl acetate, cf 1,4-dimethylindanyl acetate, dodecyl acetate, 1-octanol, octyl acetate, and decyl acetate.
Bees and flies responded similarly to the compounds, but some of the compounds were only active in flies (1-heptanol) or bees (benzyl alcohol, benzyl acetate, 2-phenylethyl acetate, hexyl acetate, nonyl acetate, indole) (Table 3).

\section{Discussion}

Our analyses of floral scent samples revealed a large number of compounds, mainly aliphatic and aromatic compounds, and terpenoids, with quantitative, qualitative, and semi-quantitative differences in scent profiles among populations. Many different insect taxa were identified as flower visitors, mainly bees at low altitudes and more syrphid flies than bees at higher altitudes, whereas bees were the most abundant pollinators at all sites. Bee and syrphid fly flower visitors/pollinators used for electrophysiological measurements responded similarly to the compounds and most of the substances available in the scent samples elicited antennal responses in both groups of insects. 
Table 3 Compounds of the two solvent scent samples of Cypripedium calceolus (S1, S2) eliciting antennal responses in Andrena and Lasioglossum bees, and a Platycheirus fly

\begin{tabular}{|c|c|c|c|c|c|c|c|}
\hline No. & Substance & $\begin{array}{l}\text { Andrena } \\
\text { bicolor } \\
\mathrm{f} \\
\mathrm{S} 1\end{array}$ & $\begin{array}{l}\text { Andrena } \\
\text { haemorrhoa } \\
\mathrm{f}\end{array}$ & $\begin{array}{l}\text { Andrena } \\
\text { cineraria } \\
\mathrm{f}\end{array}$ & $\begin{array}{l}\text { Platycheirus } \\
\text { albimanus } \\
\mathrm{f}\end{array}$ & $\begin{array}{l}\text { Platycheirus } \\
\text { albimanus } \\
\mathrm{m}\end{array}$ & $\begin{array}{l}\text { Lasioglossum } \\
\text { calceatum/albipes } \\
\mathrm{f} \\
\mathrm{S} 2\end{array}$ \\
\hline & \multicolumn{7}{|l|}{ Aliphatic compounds } \\
\hline 29 & 1-Heptanol ${ }^{1}$ & & & & + & + & \\
\hline 1 & Hexyl acetate & + & & + & & & + \\
\hline 3 & 1-Octanol & + & + & + & + & + & + \\
\hline 6 & Heptyl acetate & + & + & & + & + & + \\
\hline 11 & (E)-2-Octenyl acetate & & + & + & + & + & + \\
\hline 12 & Octyl acetate & + & + & + & + & + & + \\
\hline 16 & 1-Decanol & + & + & + & + & & + \\
\hline 17 & (Z)-3-Nonenyl acetate & + & + & + & + & + & + \\
\hline 18 & Nonyl acetate & + & + & + & & & + \\
\hline 20 & Decyl acetate & + & + & + & + & + & + \\
\hline \multirow[t]{2}{*}{31} & Dodecyl acetate & + & + & + & + & + & + \\
\hline & \multicolumn{7}{|l|}{ Aromatic compounds } \\
\hline 2 & Benzyl alcohol & + & + & + & & & + \\
\hline 30 & p-Cresol & + & + & + & + & + & - \\
\hline 7 & 2-Phenylethanol & & + & & + & + & + \\
\hline 10 & Benzyl acetate & & & & & & + \\
\hline 15 & 2-Phenylethyl acetate & & & & & & + \\
\hline 28 & cf 1,4-Dimethylindanyl acetate & + & + & + & + & + & + \\
\hline 29 & 1-Heptanol & & & & + & + & \\
\hline \multirow[t]{2}{*}{1} & Hexyl acetate & + & & + & & & + \\
\hline & \multicolumn{7}{|l|}{ Terpenoids } \\
\hline 4 & (E)-Linalool oxide furanoid & + & + & + & + & + & + \\
\hline 5 & Linalool & + & + & + & + & + & + \\
\hline 8 & 4-Oxoisophorone & + & + & + & + & + & + \\
\hline 9 & Lilac aldehyde $B$ and $C^{1}$ & - & - & - & - & - & + \\
\hline 13,14 & Lilac alcohol A-C & - & - & - & - & - & + \\
\hline 19 & Lilac alcohol formate A-C & - & - & - & - & - & + \\
\hline 21 & $(E)-\beta$-Farnesene & - & - & - & - & - & + \\
\hline 22 & $(Z, E)$ - $\alpha$-Farnesene & - & - & - & - & - & + \\
\hline 23 & $(E, E)$ - $\alpha$-Farnesene & - & - & - & - & - & + \\
\hline 25 & $(E)$-Nerolidol & + & + & + & + & & + \\
\hline \multirow[t]{2}{*}{27} & Unknown sesquiterpene & - & - & - & - & - & + \\
\hline & \multicolumn{7}{|l|}{ Nitrogen-containing compounds } \\
\hline \multirow[t]{2}{*}{32} & Indole & + & + & & & & - \\
\hline & No of EAD-active/available substances & $17 / 22$ & $18 / 22$ & $16 / 22$ & $16 / 22$ & $15 / 22$ & $26 / 28$ \\
\hline
\end{tabular}

The numbers (No.) correspond to numbers given in Figs. 6 and 7

'-' indicates a compound not present in the tested sample

${ }^{1}$ These compounds were not found in TD samples

\section{Scent}

The analysis of the floral scent of $C$. calceolus revealed 71 components, which is more than in previous studies.
Nilsson (1979) reported 11 components in this taxon, Bergstrom et al. (1992) 39 components. Despite the differences in the number of compounds detected, which might have to do with methodological progress in scent 

responses (EAD) of a female Platycheirus albimanus to flower scent (S1) of Cypripefor compounds correspond to numbers given in Table 3; these present run and/or in other runs which used this scent sample. EAD-active compounds not numbered were also found in control samples and treated as contaminants
Fig. 6 Example of antennal dium calceolus (FID). Numbers compounds were EAD-active in
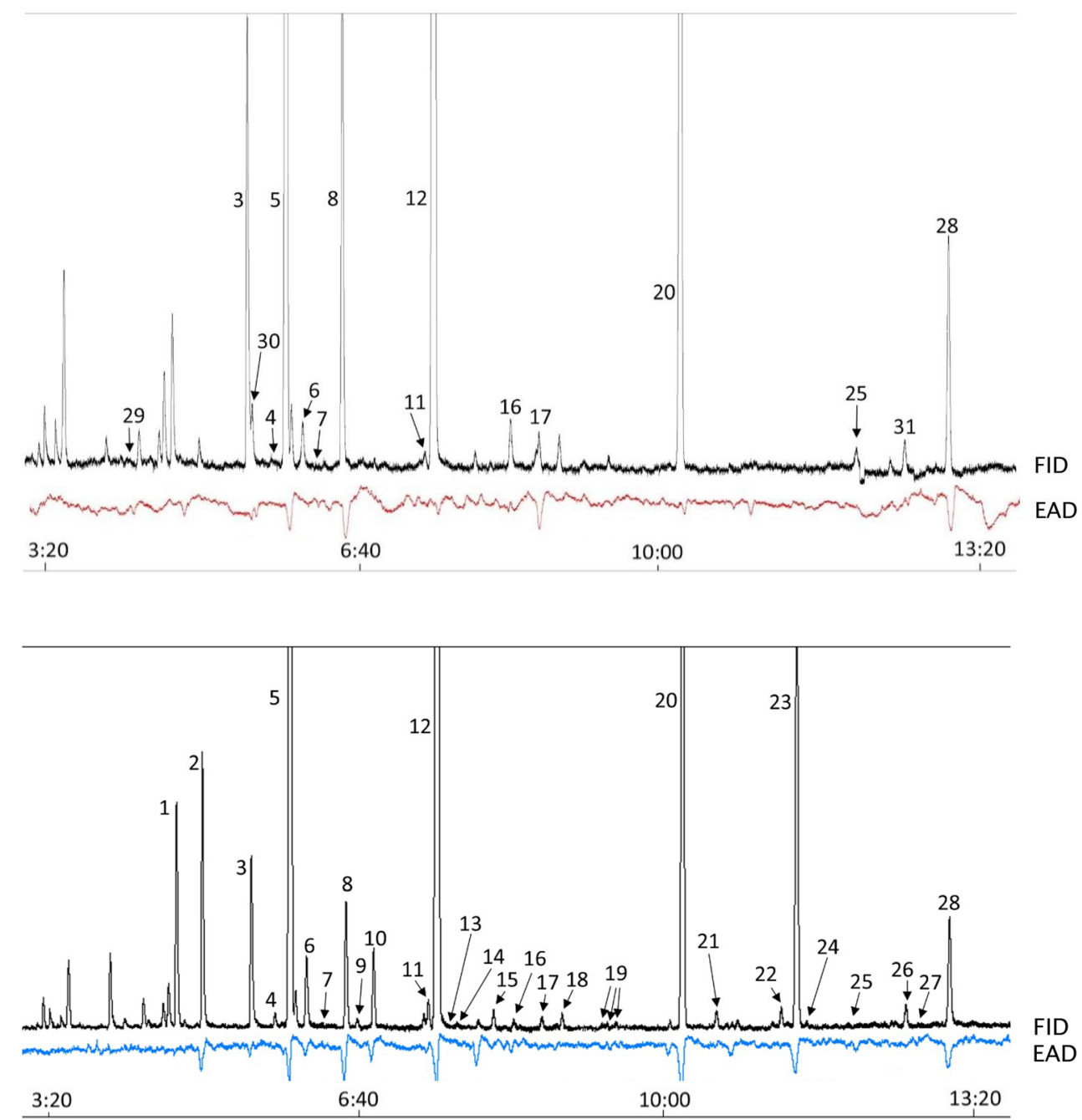

EAD
Fig. 7 Example of antennal responses (EAD) of a female Lasioglossum calceatum/albipes to flower scent (S2) of Cypripedium calceolus (FID). Numbers for compounds correspond to numbers given in Table 3; these compounds were EAD active in present run and/or in other runs which used this scent sample. EAD-active compounds not numbered were also found in control samples and treated as contaminants analyses during the last decades, our results are roughly consistent with these previous studies as we detected most of the compounds described previously. Only some minor or trace components described by Nilsson (1979) and Bergstrom et al. (1992) are not in our list (Table 1). Some thereof, such as $\alpha$-pinene and nonanal, were also available in our samples, but not included in the list as they also occurred in leaf or ambient control samples. Further, linalool was on average more abundant in our study. However, given the high variation in the relative amount of linalool released from the flowers as shown in the present study, it just might be possible that the few plants sampled by Nilsson (1979) and Bergstrom et al. (1992) were by chance ones with exceptional low amounts of linalool, though it cannot be excluded that plants in Northern Europe (used for the previous studies) generally emit smaller amounts of linalool than plants of the northern Alps.

In our study, similar high variations in the relative amounts of linalool and octyl acetate were observed and the relative amounts of these two compounds were negatively correlated (see Fig. 2). These variations overall contributed to a high intrapopulation variation in semi-quantitative scent patterns. Similarly, there was an obvious intra-population variation in the spectrum of compounds emitted, with only some compounds being emitted in most or all of the samples per specific population (Table 1). These intrapopulation variations in scent of $C$. calceolus are consistent with the finding of Ackerman et al. (2011) showing that such variations in the floral advertisement are frequently found in deceptive species.

Despite the obvious overlap in univariate (total absolute amount of scent) and multivariate (qualitative, semi-quantitative) scent properties among populations (Table 1), differences among populations were detected in all properties analyzed. Scents were population-specific, though not all populations differed from one another. Such interpopulation variations in floral scent are frequently found in angiosperms, in both mutualistic and deceptive species (Raguso 2008, and references therein). In the present study, scents 
did not vary according to altitude levels; instead, plants of the lowest and highest population were often most similar. This was especially true for quantitative and semi-quantitative scent patterns.

\section{Flower visitors and pollinators}

We identified bees as most abundant pollinators, which is consistent with previous studies performed in northern (Antonelli et al. 2009; Blinova 2002; Erneberg and Holm 1999; Ishmuratova et al. 2005; Nilsson 1979) or central (Daumann 1968; Vöth 1991) Europe, where bees were described as the only pollinators. However, we introduce several new pollinator species, and the relative contribution of Lasioglossum compared to other bees (e.g., Andrena) to the pollinator spectrum was higher in the present compared to previous studies. More importantly, we for the first time identified syrphid flies with pollen load. They were known to visit flowers of $C$. calceolus before our study (Daumann 1968; Nilsson 1979; Blinova 2002; Ishmuratova et al. 2005; Antonelli et al. 2009), but evidence that they carry pollen is just provided in the present study (Table 2; Figs. 4 and 5). Along these lines, we for the first time found a sawfly carrying pollen.

It would be interesting to know whether differences in pollinators found in our study compared to other studies are due to differences in the insects available at the different sites, due to a different attractiveness of the different scents, or due to both or other potential factors influencing the insects trapped by the flowers, such as the co-flowering plant communities. Overall, C. calceolus is pollinated by a large number of insect species from different families and even orders, suggesting that the plant has a quite generalized pollination system.

Consistent with previous studies on C. calceolus (e.g., Nilsson 1979), we found that only a subset of attracted insects acts as pollinators (13 of 42 species attracted were found carrying pollen). This partly has to do with a mismatch of the flowers' and insects' sizes (e.g., in Bombus; see also Nilsson 1979) but also seems to be due to other reasons as only a very small proportion of the attracted flies carried pollen although they were obviously of similar size as bee pollinators. Our preliminary observations suggest that, compared to bees, flies less often leave the flower through the posterior exit and some were even found dead inside the labellum. Interestingly, although flies were most abundant as flower visitors at the highest population (Wimbach), they only acted as pollinators of the two lowest populations. This only partly can be explained by a species effect. Only two of the three syrphid species occurring as pollinators at lower altitudes do not occur as visitors at the highest altitude.

\section{Electroantennographic measurements}

Our preliminary electroantennographic measurements used a scent sample from Almbach and one from Königsbach, and revealed that both bee and syrphid fly visitors/pollinators detect most of the scent substances available in the samples. Thus, the olfactory advertisement of the deceptive flowers is well perceived by the pollinators. However, our study does not prove that these compounds are involved in pollinator attraction. Behavioral experiments with natural and synthetic scent samples are necessary to finally learn about the compounds playing an important role in the deceptive strategy of the plant. Nothing was known about the compounds of $C$. calceolus and generally floral scents detected by the insect species used for the analyses before our study. Thus, our study adds a large number of compounds to the list of floral scents being biologically active in bee and syrphid fly flower visitors/pollinators (e.g., Dötterl and Vereecken 2010; Jürgens et al. 2014; Knauer and Schiestl 2015; Primante and Dötterl 2010). Bees and syrphid flies responded similarly to the compounds in our study and we detected just one compound which was exclusively EAD-active in flies (1-Heptanol) and six compounds, which were only active in bees. Two of the latter compounds (benzyl acetate, 2-phenylethyl acetate) elicited only antennal signals in a Lasioglossum bee, which was the only insect tested on sample S2, whereas these compounds were not EAD-active in sample S1, which was tested on antennae of both bees and flies. Thus, differences in perceptibility of these compounds between bees and flies may more be due to a sample effect and less a true effect of insect order.

\section{Conclusions and outlook}

Are our data consistent with the hypothesis that floral scent is adapted to the olfactory preferences of locally variable pollinator climates? If yes, we would expect that both floral scents and pollinators differ among populations in concerted manner. Although we found that scents and pollinator species differed among populations, a common pattern of variation in scent and pollinators among populations is not obvious. This is because populations most differentiated in altitude (Bartholomew, Wimbach) differed most strongly only in pollinators, but not in their scents. Nevertheless, the conclusion about the variations in scent may change when analyzing only physiologically or behaviorally active compounds. Thus, future experiments should identify compounds involved in the attraction of pollinators and test whether pollinators of the different populations respond physiologically and behaviorally stronger to local scents than to scents collected from other populations. 
Acknowledgements Open access funding provided by Paris Lodron University of Salzburg. Martin Schwarz determined the sawfly, and Johann Neumayr supported the determination of bees. Ansuela Braunschmid, Robin Guilhot, Bettina Leitner, and Maria Liebrecht helped gathering pollinators and Florian Etl took the pictures of the pollinating syrphid fly. We thank the National Park Berchtesgaden and Fritz Eder for support during field work and the District Government of Upper Bavaria for the collection permit (55.1-8645-2-2013).

Open Access This article is distributed under the terms of the Creative Commons Attribution 4.0 International License (http:// creativecommons.org/licenses/by/4.0/), which permits unrestricted use, distribution, and reproduction in any medium, provided you give appropriate credit to the original author(s) and the source, provide a link to the Creative Commons license, and indicate if changes were made.

\section{References}

Ackerman JD, Cuevas AA, Hof D (2011) Are deception-pollinated species more variable than those offering a reward? Plant Syst Evol 293:91-99. doi:10.1007/s00606-011-0430-6

Aigner PA (2001) Optimality modeling and fitness trade-offs: when should plants become pollinator specialists? Oikos 95(1):177184. doi: $10.2307 / 3547362$

Amiet F (1996) Hymenoptera. Apidae. 1. Teil, Allgemeiner Teil, Gattungsschlüssel, Gattungen Apis, Bombus und Psithyrus. Insecta Helvetica 12. Schweizerische Entomologische Ges., Lausanne

Amiet F, Herrmann M, Müller A, Neumeyer R (2001) Apidae 3: Halictus, Lasioglossum. Fauna Helvetica 6. CSF \& SEG, Neuchâtel

Amiet F, Herrmann M, Müller A, Neumeyer R (2004) Apidae 4: Anthidium, Chelostoma, Coelioxys, Dioxys, Heriades, Lithurgus, Megachile, Osmia, Stelis. Fauna Helvetica 9. CSF \& SEG, Neuchâtel

Amiet F, Herrmann M, Müller A, Neumeyer R (2007) Apidae 5: Ammobates, Ammobatoides, Anthophora, Biastes, Ceratina, Dasypoda, Epeoloides, Epeolus, Eucera, Macropis, Melecta, Melitta, Nomada, Pasites, Tetralonia, Thyreus, Xylocopa. Fauna Helvetica 20. CSF \& SEG, Neuchâtel

Amiet F, Herrmann M, Müller A, Neumeyer R (2010) Apidae 6: Andrena, Melitturga, Panurginus, Panurgus. Fauna Helvetica 26. CSF \& SEG, Neuchatel

Andargie M, Knudsen JT, Pasquet RS, Gowda BS, Muluvi GM, Timko MP (2014) Mapping of quantitative trait loci for floral scent compounds in cowpea (Vigna unguiculata L.). Plant Breed 133(1):92-100. doi:10.1111/pbr.12112

Anderson M, Gorley RN, Clarke RK (2008) Permanova+ for Primer: guide to software and statistical methods. PRIMER-E Ltd., Plymouth

Antonelli A, Dahlberg CJ, Carlgren, KHI, Appelqvist T (2009) Pollination of the lady's slipper orchid (Cypripedium calceolus) in Scandinavia-taxonomic and conservational aspects. Nordic J Bot 27(4):266-273. doi:10.1111/j.1756-1051.2009.00263.x

Bergstrom G, Birgersson G, Groth I, Anders Nilsson L (1992) Floral fragrance disparity between three taxa of lady's slipper Cypripedium calceolus (Orchidaceae). Phytochemistry 31(7):23152319. doi:10.1016/0031-9422(92)83271-Y

Blinova IV (2002) A northernmost population of Cypripedium calceolus L. (Orchidaceae): demography, flowering, pollination. Selbyana 23:111-120

Brzosko E, Wróblewska A, Ratkiewicz M (2002) Spatial genetic structure and clonal diversity of island populations of lady's slipper (Cypripedium calceolus) from the Biebrza National Park (northeast Poland). Mol Ecol 11(12):2499-2509. doi:10.1046/j.1365-294X.2002.01630.x

Chartier M, Pélozuelo L, Buatois B, Bessière JM, Gibernau M (2013) Geographical variations of odour and pollinators, and test for local adaptation by reciprocal transplant of two European Arum species. Funct Ecol 27(6):1367-1381. doi:10.1111/1365-2435.12122

Chittka L, Raine NE (2006) Recognition of flowers by pollinators. Curr Opin Plant Biol 9(4):428-435. doi:10.1016/j. pbi.2006.05.002

Clarke KR, Gorley RN (2006) Primer v6: user manual/tutorial. Primer-E, Plymouth

Cordeiro G, Pinheiro M, Dötterl S, Alves-dos-Santos I (2017) Pollination of Campomanesia phaea (Myrtaceae) by night-active bees: a new nocturnal pollination system mediated by floral scent. Plant Biol 19:132-139. doi:10.1111/plb.12520

Cribb P (1997) The genus Cypripedium. Timber Press, Portland

Daumann E (1968) Zur Bestäubungsökologie von Cypripedium calceolus L. Österreichische Botanische Zeitschrift 115(4-5):434446. doi:10.1007/BF01456538

Dobson HEM (2006) Relationship between floral fragrance composition and type of pollinator. In: Dudareva N, Pichersky E (eds) Biology of floral scent. CRC Press, Boca Raton, pp 147-198

Dötterl S, Vereecken NJ (2010) The chemical ecology and evolution of bee-flower interactions: a review and perspectives. Can J Zool 88(7):668-697. doi:10.1139/Z10-031

Dötterl S, Wolfe LM, Jürgens A (2005) Qualitative and quantitative analyses of flower scent in Silene latifolia. Phytochemistry 66(2):203-213. doi:10.1016/j.phytochem.2004.12.002

Dötterl S, David A, Boland W, Silberbauer-Gottsberger I, Gottsberger G (2012) Evidence for behavioral attractiveness of methoxylated aromatics in a dynastid scarab beetle-pollinated Araceae. J Chem Ecol 38(12):1539-1543. doi:10.1007/s10886-012-0210-y

Erneberg M, Holm B (1999) Bee size and pollen transfer in Cypripedium calceolus (Orchidaceae). Nordic J Bot 19(3):363-367. doi:10.1111/j.1756-1051.1999.tb01128.x

Friberg M, Schwind C, Raguso RA, Thompson JN (2013) Extreme divergence in floral scent among woodland star species (Lithophragma spp.) pollinated by floral parasites. Ann Bot (Lond) 111(4):539-550. doi:10.1093/aob/mct007

Gokcezade JF, Gereben-Krenn B-A, Neumayer J, Krenn HW (2010) Feldbestimmungsschlüssel für die Hummeln Österreichs, Deutschlands und der Schweiz. Linzer Biologische Beiträge 42:5-42

Grant V, Grant KA (1965) Flower pollination in the Phlox family. Columbia University Press, New York

Heiduk A, Kong H, Brake I, Von Tschirnhaus M, Tolasch T, Tröger AG et al (2015) Deceptive Ceropegia dolichophylla fools its kleptoparasitic fly pollinators with exceptional floral scent. Front Ecol Evol. doi:10.3389/fevo.2015.00066

Heiduk A, Brake I, von Tschirnhaus M, Göhl M, Jürgens A, Johnson SD et al (2016) Ceropegia sandersonii mimics attacked honeybees to attract kleptoparasitic flies for pollination. Curr Biol 26(20):2787-2793. doi:10.1016/j.cub.2016.07.085

Ishmuratova MM, Zhimova TV, Ishbirdin AR, Sujundukov IV, Magafurov AM (2005) Antecology, phenology and consorts of Cypripedium calceolus $\mathrm{L}$. and Cypripedium guttatum $\mathrm{Sw}$. in the southern Ural. Bull Mosc Soc Nat 110

IUCN (2015) The IUCN Red List of Threatened Species. Version 2015-4. http://www.iucnredlist.org

Johnson SD (1997) Pollination ecotypes of Satyrium hallackii (Orchidaceae) in South Africa. Bot J Linn Soc 123:225-235

Johnson SD (2006) Pollinator-driven speciation in plants. In: Harder LD, Barrett SCH (eds) Ecology and evolution of flowers. Oxford University Press, Oxford, pp 295-310 
Jürgens A, Glück U, Aas G, Dötterl S (2014) Diel fragrance pattern correlates with olfactory preferences of diurnal and nocturnal flower visitors in Salix caprea (Salicaceae). Bot J Linn Soc 175(4):624-640. doi:10.1111/boj.12183

Knauer AC, Schiestl FP (2015) Bees use honest floral signals as indicators of reward when visiting flowers. Ecol Lett 18(2):135-143. doi:10.1111/ele.12386

Knudsen J, Eriksson R, Gershenzon J, Ståhl B (2006) Diversity and distribution of floral scent. Bot Rev 72(1):1-120. doi:10.1663/0006-8101(2006)72[1:dadofs]2.0.co;2

Kull T (1998) Fruit-set and recruitment in populations of Cypripedium calceolus L. in Estonia. Bot J Linn Soc 126(1-2):27-38. doi:10.1111/j.1095-8339.1998.tb02513.x

Kull T (1999) Cypripedium calceolus. J Ecol 87:913-924

Mant J, Peakall R, Schiestl FP (2005) Does selection on floral odor promote differentiation among populations and species of the sexually deceptive orchid genus Ophrys? Evol Int J org Evol 59(7):1449. doi:10.1554/04-547

Marke T, Strasser U, Kraller G, Warscher M, Kunstmann H, Franz H, Vogel M (2013) The Berchtesgaden National Park (Bavaria, Germany): a platform for interdisciplinary catchment research. Environ Earth Sci 69(2):679-694. doi:10.1007/s12665-013-2317-z

Milet-Pinheiro P, Ayasse M, Dobson, H. E. M., Schlindwein C, Francke W, Dötterl S (2013) The chemical basis of host-plant recognition in a specialized bee pollinator. J Chem Ecol 39(1112):1347-1360. doi:10.1007/s10886-013-0363-3

Mitchell TC, Dötterl S, Schaefer H (2015) Hawk-moth pollination and elaborate petals in Cucurbitaceae: the case of the Caribbean endemic Linnaeosicyos amara. Flora 216:50-56. doi:10.1016/j. flora.2015.08.004

Nilsson LA (1979) Anthecological studies on the Lady's slipper, Cypripedium calceolus (Orchidaceae). Bot Notiser 132(132):329-347

Ollerton J, Winfree R, Tarrant S (2011) How many flowering plants are pollinated by animals? Oikos 120(3):321-326. doi:10.1111/j.1600-0706.2010.18644.x

Pellmyr O (1986) Three pollination morphs in Cimicifuga simplex; incipient speciation due to inferiority in competition. Ecology 68(2):304-307

Primante C, Dötterl S (2010) A syrphid fly uses olfactory cues to find a non-yellow flower. J Chem Ecol 36(11):1207-1210. doi:10.1007/s10886-010-9871-6
Raguso RA (2008) Wake up and smell the roses: the ecology and evolution of floral scent. Annu Rev Ecol Evol Syst 39(1):549-569. doi:10.1146/annurev.ecolsys.38.091206.095601

Renner SS (2006) Rewardless flowers in the angiosperms and the role of insect cognition in their evolution. In: Waser NM, Ollerton J (eds) Plant-pollination interactions: from specialization to generalization. The University of Chicago Press, Chicago, pp 123-144

Schäffler I, Steiner KE, Haid M, van Berkel SS, Gerlach G, Johnson SD et al (2015) Diacetin, a reliable cue and private communication channel in a specialized pollination system. Sci Rep. doi:10.1038/srep12779

Scheuchl E, Willner W (2016) Taschenlexikon der Wildbienen Mitteleuropas. Wiebelsheim: Quelle \& Meyer Verlag

Schiestl FP, Ayasse M, Paulus HF, Löfstedt C, Hansson BS, Ibarra F, Francke W (1999) Orchid pollination by sexual swindle. Nature 399(6735):421-421. doi:10.1038/20829

Smith KA (2003) A simple multivariate technique to improve the design of a sampling strategy for age-based fishery monitoring. Fish Res 64(1):79-85

Speight MCD, Sarthou JP (2014) StN key for the identification of the genera of European Syrphidae (Diptera). Syrph the Net, the database of European Syrphidae. Syrph the Net Publications, Dublin

Stökl J, Schlüter PM, Stuessy TF, Paulus HF, Fraberger R, Erdmann D et al (2009) Speciation in sexually deceptive orchids: pollinator-driven selection maintains discrete odour phenotypes in hybridizing species. Biol J Linn Soc 98(2):439-451. doi:10.1111/j.1095-8312.2009.01279.x

Sun M, Gross K, Schiestl FP (2014) Floral adaptation to local pollinator guilds in a terrestrial orchid. Ann Bot (Lond) 113(2):289300. doi:10.1093/aob/mct219

Vöth W (1991) Cypripedium calceolus L. (Orchidaceae) in Niederösterreich. Linzer Biol Betr 23(2):537-566

Waser NM (2001) Pollinator behavior and plant speciation: looking beyond the "ethological isolation" paradigm. In: Chittka L, Thomson JD (eds) Cognitive ecology of pollination. Cambridge University Press, Cambridge, pp 318-335

Zu P, Blanckenhorn WU, Schiestl FP (2016) Heritability of floral volatiles and pleiotropic responses to artificial selection in Brassica rapa. New Phytol 209(3):1208-1219. doi:10.1111/nph.13652 